\title{
Maculopapular eruption and fever due to lamotrigine followed by subsiding flare-ups
}

\author{
Anna Valerieva", Maria Staevska, Vasil Dimitrov, Todor Popov \\ From EAACI Skin Allergy Meeting 2014 \\ Krakow, Poland. 18-20 September 2014
}

\section{Introduction}

Lamotrigine (LTG), an aromatic antiepileptic drug, is mainly used to manage epilepsy and bipolar / mood disorders. Skin rashes are the most common adverse reaction to this drug that typically develop in the first 8 weeks of treatment.

\section{Case presentation}

A 27-year-old Caucasian woman treated with LTG $25 \mathrm{mg}$ PO for a depressive episode was hospitalized in our allergy clinic with highly pruritic maculopapular eruption (MPE), affecting her abdomen, chest, back and forearms, which had started 2 days earlier along with fever of $37.5^{\circ} \mathrm{C}$. A well-defined red dermographism and tenderness of the skin was observed. She had been prescribed LTG 8 days before the symptoms commenced. A LTGinduced drug rash was suspected and the offending drug was therefore withdrawn.

The patient was prescribed methylprednisolone 60 $\mathrm{mg} / \mathrm{d}$ IV, bilastine $2 \times 20 \mathrm{mg} / \mathrm{d} \mathrm{PO}$, and chloropyramine $25 \mathrm{mg}$ IM in the evening. Topical skin care with emollients was started, as well.

All blood and urine laboratory tests were within reference ranges except for the hsCRP of $9.6 \mathrm{mg} / \mathrm{l}$ (reference values up to $5 \mathrm{mg} / \mathrm{l}$ ). Abdominal ultrasonography was performed and was unremarkable. The lesions subsided 7 days after starting the treatment. The patient was discharged with a prescription for methylprednisolone $20 \mathrm{mg} / \mathrm{d}$ PO, bilastine $20 \mathrm{mg} / \mathrm{d} \mathrm{PO}$ and topical emollient skin care.

13 days later a new flare-up of MPE occurred. Again, laboratory tests were normal. The patient was prescribed methylprednisolone $40 \mathrm{mg} / \mathrm{d}$ IV, bilastine $2 \times 20 \mathrm{mg} / \mathrm{d}$ PO and emollients. The eruption sustained for 3 weeks with frequent flare-ups. The corticosteroids' regimen was adapted promptly with step downs and ups in order to maintain the severity of the symptoms. Antihistamines and emollients helped releive the subjective symptoms.

\section{Conclusion}

MPE due to LTG is a common drug-induced hypersensitivity reaction. This reaction is generally mild. However, reactions should be monitored closely as they can be refractory and relapsing. This case presentation provides evidence that challenge tests should be performed at least 2 months after the discontinuation of the suspected drug, for there is a risk of false-positive reactions due to subsiding flare-ups.

\section{Consent}

Written informed consent was obtained from the patient for publication of this abstract and any accompanying images. A copy of the written consent is available for review by the Editor of this journal.

Published: 11 March 2015

doi:10.1186/2045-7022-5-S1-P13

Cite this article as: Valerieva et al:: Maculopapular eruption and fever due to lamotrigine followed by subsiding flare-ups. Clinical and Translational Allergy 2015 5(Suppl 1):P13. 